\title{
An unusual giant serpiginous lesion of secondary syphilis*
}

\author{
Xavier Grimaux ${ }^{1}$, Rida El Ayoubi ${ }^{2}$, Christian Le Clec' ${ }^{1}$
}

DOI: http:/ / dx.doi.org/10.1590/abd1806-4841.20187251

Abstract: Syphilis is a worldwide sexually transmitted infection caused by Treponema pallidum subspecies pallidum. Its association with other STIs, including HIV, demands early diagnosis and immediate treatment of patients. We herein report an unusual serpiginous form of secondary syphilis.

Keywords: HIV; Sexually transmitted diseases; Syphilis

A 35-year-old man presented to the dermatology department with massive asymptomatic palmoplantar lesions. He did not experience weight loss or impaired general condition. Clinical examination revealed the presence of significant serpiginous palmoplantar erosions as well as lingual and genital erosions (Figure 1). Oral lesions were moderately painful. The patient had condomless homosexual intercourse six months earlier. Treponema pallidum hemagglutination (TPHA) and Venereal Disease Research Laboratory (VDRL) tests were both positive. He underwent screening for other sexually transmitted infections, including hepatitis B and C viruses and HIV serology tests; all the tests were negative. He received one dose of intramuscular penicillin $\mathrm{G}$ benzathine.

Following a phase of significant decrease in the incidence of syphilis during the second half of the 20th century, an upsurge in cases has been observed since the early 2000s, especially among men who have sex with men. ${ }^{1}$

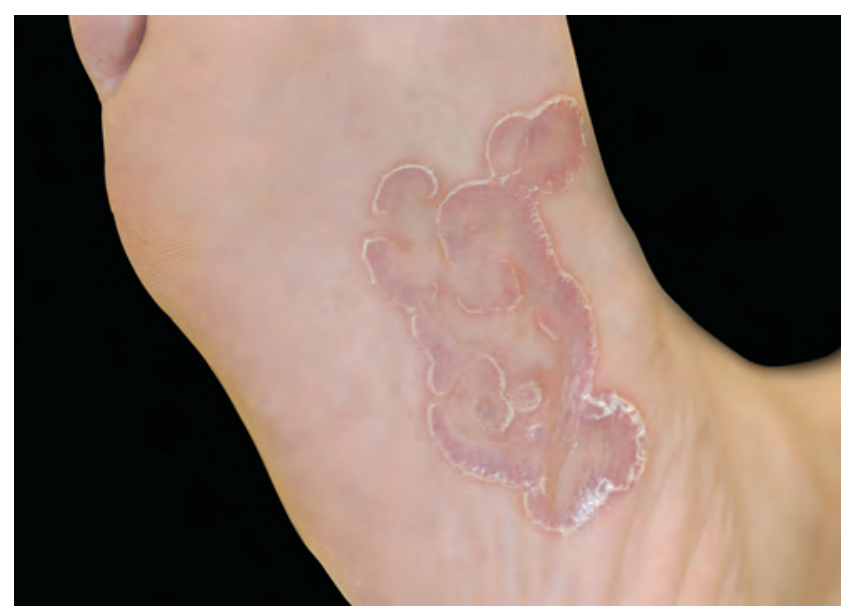

FIGURE 1: A giant serpiginous plantar syphilid

\footnotetext{
Received 29 April 2017.

Accepted 23 Juny 2017.

* Work conducted at the Dermatology Department, Centre Hospitalier et Universitaire Angers, France

Financial Support: None.

Conflict of Interest: None.

1 Service de Dermatologie, Centre Hospitalier et Universitaire, Angers, France

2 Laboratoires de cytologie et d'anatomopathologie, Centre Hospitalier Universitaire, Angers, France
}

\section{MAILING AdDRESS:}

Xavier Grimaux

E-mail: xavierroger.grimaux@gmail.com 
Secondary syphilis ("the great imitator") is a multifaceted disease characterized by a multistage evolution involving a total of three clinical stages.

The classic form of secondary syphilis, corresponding to the systemic passage of Treponema pallidum, is characterized at onset by the appearance of localized or diffuse pink-to-brown papules. Subsequently, disseminated papulosquamous lesions of typically very small size appear. Palmoplantar involvement is frequent. Oral lesions are characteristically well-delineated, erythematous, erosive and painless. Our patient presented with an atypical cutaneo-mucous form, desquamative serpiginous palmoplantar lesions of large size, as well as oral pemphigus-like involvement causing moderate pain.

The clinical spectrum of syphilis is characterized by its astonishing diversity and the frequent occurrence of atypical clinical

\section{REFERENCES}

1. Taylor MM, Aynalem G, Olea LM, He P, Smith LV, Kerndt PR. A consequence of the syphilis epidemic among men who have sex with men (MSM): neurosyphilis in Los Angeles, 2001-2004. Sex Transm Dis. 2008;35:430-4.

2. Balagula Y, Mattei PL, Wisco OJ, Erdag G, Chien AL. The great imitator revisited: the spectrum of atypical cutaneous manifestations of secondary syphilis. Int J Dermatol. 2014;53:1434-41.

3. Fukuda H, Takahashi M, Kato K, Oharaseki T, Mukai $\mathrm{H}$. Multiple primary syphilis presentations, which are seen in 30 percent of infected patients. ${ }^{2}$ Many clinical manifestations have already been reported, such as annular, nodular, noduloulcerative, (lues maligna), pustular, acneiform, framboesiform, corymbose, photosensitive systemic lupus erythematosus (SLE)-like, leukoderma, pityriasis lichenoides-like and chancriform morphologic patterns. ${ }^{3,4}$

Histologic findings are variable. Thus, when a mucous or cutaneous sample is taken, an immunohistochemistry test using an anti-T. pallidum antibody should be performed in combination with standard histologic stains in order to make the diagnosis. ${ }^{2,3}$

Here, we report an atypical serpiginous form of syphilis revealed by palmoplantar lesions. We believe that it is crucial to consider a diagnosis of syphilis in any unusual dermatosis presentation with predominant palmoplantar affection.

on the lip, nipple-areola and penis: An immunohistochemical examination of Treponema pallidum localization using an anti-T. pallidum antibody. J Dermatol. 2015;42:515-7.

4. Lee EH, Lee JH, Kim DH, Yoon MS, Lee SE. Solitary framboesiform syphilid on the scalp. J Dermatol 2012; 39: 568569

\section{AUTHORS CONTRIBUTION}

Xavier Grimaux

\section{(iD) ORCID 0000-0003-2752-5766}

Approval of the final version of the manuscript; Elaboration and writing of the manuscript; Obtaining, analyzing and interpreting the data; Intellectual participation in proCritical review of the manuscript

Rida El Ayoubi

ORCID 0000-0001-7074-6009

Approval of the final version of the manuscript; Intellectual participation in propaedeutic and/or therapeutic conduct of cases studied; Critical review of the literature

\section{Christian Le Clec'h \\ ORCID 0000-0002-8509-3642}

Approval of the final version of the manuscript; Effective participation in research orientation; Intellectual participation in propaedeutic and/or therapeutic conduct of cases studied

How to cite this article: Grimaux X, El Ayoubi R, Le Clec'h C. An unusual giant serpiginous lesion of secondary syphilis. An Bras Dermatol. 2018;93(4):590-1. 